\title{
Application and Exploration of Virtual Simulation Experiment Technology in Medical Comprehensive Design Experiment
}

\author{
Liping Yang* \\ Henan University of Traditional Chinese Medicine \\ HCUM \\ Zhengzhou, Henan, China
}

\author{
Fengjuan Ye \\ Henan University of Traditional Chinese Medicine \\ HCUM \\ Zhengzhou, Henan, China
}

\author{
Mingmin Pan \\ Henan University of Traditional Chinese Medicine \\ HCUM \\ Zhengzhou, Henan, China
}

\begin{abstract}
To summarize the problems of virtual simulation experiments and point out the direction for its development, this paper summarizes the current situation of medical virtual simulation experiment teaching and the necessity of its implementation, establishes the process and method system of virtual simulation experiment platform, and introduces the advantages of virtual simulation technology in medical comprehensive design experiment. The virtual simulation experiment teaching still faces problems in project research and development, resource allocation and assessment system. The application of virtual simulation experiment technology in medical comprehensive design is in its initial stage, and it still needs to optimize the content and process of virtual simulation experiment teaching, to provide new methods and means for better improving the quality of medical education and promoting the progress of medical education.
\end{abstract}

Keywords-Comprehensive Design of Medicine; Virtual Simulation Experiment; Technology; Education

\section{INTRODUCTION}

"Comprehensive Design Experiment in Medicine" is a comprehensive design experiment course that students use the basic knowledge, skills, and methods they have mastered to select topics, design and implement independently. There are many problems in the project-based teaching method of traditional medicine comprehensive design experiment teaching[1], which takes the project as the mainline, the student as the leading factor and the laboratory as the base.

1. The variety of experiment contents lea to the complexity and variety of required technologies, while it is difficult for teachers to master all types of technologies because of their limited specialty. 2. Due to financial and time constraints, it is impossible to carry out pre-experiments on many technologies.

This paper was supported by the application of virtual simulation experiment technology in a medical comprehensive design experiment.[Grant No. (2018)-- JKGHYB - 0125]; and also supported by 2017 annual education and teaching reform research project of Henan University of Traditional Chinese Medicine [Grant No.2017JX45]; and standardization construction of general education database for postgraduates[Grant No.2017YJX007]
3. Repeated traumatic operations on experimental animals do not meet the requirements of animal ethics, at the same time the irregular operations may increase the risk of injury for students. 4. The traditional live demonstration has a limited audience and cannot achieve full coverage. 5. Teachers who guide multiple projects at the same time unable to follow up and guide the whole process owing to their limited energy and the failure rate of students is relatively high. To sum up, the traditional experimental teaching methods can no longer meet the needs of the new experimental teaching content, and it is urgent to introduce new technical means to improve the teaching level. The virtual simulation experiment teaching mode is an important educational system reform of the Ministry of Education, which "deepens the reform of information education teaching and realizes the overtaking of higher education". It integrates modern information technology with education teaching deeply, improves the teaching quality and promotes the international development of higher education. This study intends to introduce virtual simulation experiment technology into the course of "Comprehensive Design Experiments in Medicine" and gradually form an experimental teaching system combining online and offline.

\section{The CuRrent Situation OF Medical ViRtual SIMULATION EXPERIMENT TEACHING}

Since 2013, the Ministry of Education has entrusted the China Institute of Higher Education to select 300 national virtual simulation experimental teaching centers through procedures such as formal review, expert review and online publicity, among which 39 medical-related national virtual simulation experimental teaching centers have been selected [2-4].To further implement General Secretary Xi Jinping's important direction on strengthening practical education, the Ministry of Education issued a Notice on the Construction of Demonstration Virtual Simulation Experiment Teaching Projects from 2017 to 2020, in July 2017. It plans to build 1,000 projects in physics, chemistry, astronomy, and other 
fields, with construction plans of 100, 250, 300 and 350 respectively. It has been confirmed that the first batch of national virtual simulation experiment teaching projects has 105 in total and 50 medical-related projects, which distributed in areas like in clinical medicine, pharmacy, and biological science. In 2018, 296 national virtual simulation experiment teaching projects were selected, and 105 of them were related to medicine distributing in many disciplines such as basic medicine, clinical medicine, traditional Chinese medicine and pharmacy [5-8].

Developing virtual simulation experiment teaching is an important measure to improve the quality and level of experiment teaching. With the development of modern information technology and higher education, this teaching model has gradually attracted the attention of various universities and countries and plays an irreplaceable role in the field of medical education. Therefore, it is of great practical significance to design and implement the teaching content of virtual simulation experiments in the course of "Comprehensive Design Experiment of Medicine".

\section{CONSTRUCTION OF VIRTUAL SIMULATION EXPERIMENT TEACHING PLATFORM FOR "COMPREHENSIVE DESIGN EXPERIMENT OF MEDICINE"}

\section{A. Platform Construction and Material Database Establishment}

Medical comprehensive design experiment is a comprehensive experiment based on basic medicine, clinical medicine, microbiology, pharmacology, and other basic fields. Therefore, the construction of its platform and material library should have connectivity and comprehensiveness. Referring to the structural model of the medical virtual simulation experiment teaching platform built on windows, mobile APP(android or IOS) and other platforms, the medical comprehensive design experiment teaching platform is mainly divided into two parts: experiment content handout and virtual operating system. The online content of virtual experiments includes literature review methodology, literature management software operation, animal behavior analysis technology, commonly used instrument operation essentials and commonly used molecular biology technology, etc. Through a series of processes of script making, video recording and later debugging, the data is informationized, thus realizes resource sharing in a real sense. For projects with complex technology, huge cost, and no practical development, drawing on the experience of other colleges and universities, a virtual operating system is made to build highly simulated virtual experimental objects and experimental environment. The method of school-enterprise cooperation was adopted to develop new projects in stages and steps that conform to the teaching syllabus to meet the needs of experimental teaching.

\section{B. Virtual Simulation Experiment Operation}

The formulation of modules and processes of the virtual comprehensive design course is based on each link of the experiment, and the experimental process includes seven links of topic design, design of experiment scheme, application of consumables, pre-experiment, formal experiment, writing of conclusion report and report defense. According to each process of the experiment, the module is designed and the process and the quality of the experiment are controlled by the mode of breaking through the customs. Only after each module passes the customs can it enter the next experiment. The topic design module mainly plays a guiding role which can be exemplified by teaching students how to design topic ideas and specific experimental programs; the module of designing the experimental scheme is mainly designed by students themselves and guided by teachers. In the procedure of reporting consumables, students calculate, inquire and summarize the consumption of experimental consumables, reagents, and drugs. The pre-experiment module can be understood and some experimental operations skills can be acquired in advance through virtual experiment operation, such as instrument use, index observation, animal behavior evaluation, etc. The formal experiment was carried out according to the designed experimental scheme, with many people working in groups. A series of procedures as project report writing, report defense making, the students' processing experimental results inspection, PPT production and thinking ability, and the quality of the project report shall be reviewed by the teaching teacher [9].

\section{Learning Effect Feedback and Teacher-student Communication System}

Assessment is an effective way to a feedback learning effect in the teaching process. Virtual experiment assessment is mainly divided into two parts: routine assessment and final assessment. Regular assessment includes online learning duration, frequency, problem discussion, and periodic testing. After the completion of the tasks assigned in each link, periodic test questions will be automatically and randomly generated to conduct a real-time assessment on the learning situation of the students, so that the next link of learning can be carried out after reaching the level of passing or above. The final examination is mainly a comprehensive examination of the experimental contents through theoretical tests and skill operations, aiming at consolidating theoretical knowledge and detailed problems in experimental operations. The assessment can be monitored against the whole background so that teachers can grasp the students' learning situation immediately and supervise and guide them. Students can also communicate and interact with teachers through the learning platform. By interacting with teachers through this learning platform, students can have a good understanding of experimental scheme design improvement and independent innovation research projects so that their innovation ability can be effectively enhanced. What's more, it also gives full play to teachers' resources.

\section{AdVANTAges of InTRODUCing ViRtual SimUlation TECHNOLOGY INTO "COMPREHENSIVE DESIGN EXPERIMENT OF MEDICINE"}

\section{A. Overcoming Time and Space Constraints}

Virtual simulation experiment teaching breaks through the limitations of traditional experiment teaching on time, space and experimental instruments. Students can operate and learn 


\section{Problems in Virtual Simulation ExPERIMENT TEACHING}

anywhere, which not only saves the experiment cost but also enables multiple experiment groups to operate the same experiment module at the same time, to realize the maximum utilization of time and space. With the support of information technology at this stage, each student has the opportunity to complete a complete set of experimental operations independently, so that students can fully master the theoretical knowledge and skill operation in all aspects of the experiment.

\section{B. Enriching Experimental Teaching Content}

Using virtual simulation technology, the combination of online and offline is adopted to promote the in-depth integration of information technology and practical teaching, and to promote the integration of students' multidisciplinary knowledge points. It provides feasibility for experiments-difficult to operate in practice, involving the high-risk environment, and violate animal ethics and other issues. It is conducive to the cultivation of students' professional ethics and code of conduct at the same time; it avoids the risks existing in experiments and ensures the safety of teachers and students. With the research and development of the virtual simulation experiment project, the content of the experiment is becoming more and more abundant, and the requirements of experimental teaching and scientific research are continuously met.

\section{Improving the Efficiency of Experimental Teaching}

The virtual simulation experiment platform constructs teacher-student interaction links, and adopts online discussion and offline communication to carry out interactive and discussion-based teaching, which effectively solves the problems of the limited audience in traditional teaching, achieves comprehensive coverage, and effectively reduces the failure rate of experiments. In the process of transforming traditional experiment to virtual experiment, the pure teacher power is transformed into mixed education power, which reduces some unnecessary investment in human, material and financial resources. The reasonable allocation of resources reduces the workload of teachers, contributes to the improvement of teachers' information teaching level, and promotes the steady improvement of experimental teaching efficiency.

\section{All-round Cultivation of Innovative Talents}

Based on the principle of students-oriented, virtual simulation experiment teaching attaches great importance to the comprehensive cultivation of students' theoretical quality, practical ability, and innovative spirit, and fully arouses the enthusiasm of students to participate in experiment teaching through innovative and diverse teaching methods. On the virtual simulation experiment platform, students can use the existing virtual instrument system to choose their subjects, design their experiments and verify the feasibility of the experiments. This method of autonomous inquiry learning can fully stimulate students' interest and potential in learning, enhance students' innovative spirit and the ability of independent thinking, overall, it is conducive to the cultivation of innovative talents.
As a new force in the education system, virtual simulation experiment teaching still need to be improved in its various aspects. First of all, the research and development of the virtual simulation experiment teaching project are difficult. Its production time is long, its technical content is hard, and its cost is high. It is difficult to build a professional teaching project research and development team. To realize the sustainable development of virtual simulation teaching, a more perfect mechanism is needed. Secondly, in the experimental teaching system of combining reality with reality, a series of questions like how to reasonably allocate the proportion of teachers' face-to-face teaching and students' self-study on the basis of "taking reality as the main factor and taking empty as the auxiliary factor" and how to organically combine traditional courses with virtual courses to maximize the teaching quality still need to be further explored. Finally, the combination of online and offline teaching mode virtually increases students' learning pressure. Many contents require students to learn by themselves and have higher requirements for students. How to reduce students' learning pressure as much as possible under the premise of ensuring teaching quality needs further exploration.

\section{SUMMARY AND PROSPECT}

With the continuous development of modern information technology, virtual simulation technology has been applied to various fields, and the technology has also been introduced into comprehensive medical design experiments so that the quality of experimental teaching has been improved greatly. Virtual simulation experiments are now exerting a significant impact on making up for the shortcomings of traditional experimental teaching. The two are combined and independent of each other and play an irreplaceable role together. Conforming to the development of the times and relying on modern information technology, this educational reform comprehensively improves student's practical ability and innovative spirit, thus further promote the teaching quality in higher education. At present, the virtual simulation experiment teaching is in the construction stage, and many problems have not yet been discovered, and still need to be continuously explored and improved. With the unremitting efforts of most people, virtual simulation technology will continue to optimize and lead the new era of education, playing a vital role in the teaching development of "Comprehensive Design Experiments in Medicine".

\section{REFERENCES}

[1] Yang Liping, Li Xinmin, Hou Junlin, et al. Characteristics and Innovation of Comprehensive Design Experimental Courses in Medicine [J]. Chinese medicine modern distance education of china, 2019,17(07):31-33. (In Chinese)

[2] Ministry of Education. Notice of the General Office of the Ministry of Education on Approving 100 National Virtual Simulation Experimental Teaching Centers such as Beijing University's Earth Science Virtual Simulation Experimental Teaching Center (Gao Ting Han [2014] No.6) [Z] 2014-02-19.(In Chinese) 
[6] Ministry of Education. Notice of the Ministry of Education on the Construction of National Virtual Simulation Experiment Teaching Project (Gao Han [2018] No.5) [Z]. 2018-05-30.(In Chinese)

[3] Ministry of Education. Notice of the General Office of the Ministry of Education on Approving 100 National Virtual Simulation Experimental Teaching Centers such as Tsinghua University Digital Manufacturing System Virtual Simulation Experimental Teaching Center (Gao Ting Han [2015] No.3) [Z]. 2015-01-08.(In Chinese)

[4] Ministry of Education. Notice of the General Office of the Ministry of Education on Approving 100 National Experimental Teaching Demonstration Centers such as Tsinghua University Automation Experimental Teaching Center (Gao Ting Han [2016] No.7) [Z]. 201601-26.(In Chinese)

[5] Ministry of Education. Notice of the General Office of the Ministry of Education on the Construction of Demonstration Virtual Simulation Experiment Teaching Project from 2017 to 2020 (No.4 [Z] of the Ministry of Education [2017]. 2017-07-11.(In Chinese)

[7] Ministry of Education. Notice of the Ministry of Education on Announcing the Results of the First National Virtual Simulation Experiment Teaching Project (Gao Han [2018] No.6) [Z]. 2018-0531.(In Chinese)

[8] Ministry of Education. Notice of the Ministry of Education on Announcing the Results of 2018 National Virtual Simulation Experiment Teaching Project (Gao Han [2019] No.6) [Z]. 2019-0306.(In Chinese)

[9] Gong Man, Sun Huijuan, Zhang Minghao, et al. Virtual Simulation Curriculum Design of Comprehensive Design Experiments [J]. Educational Modernization, 2017,4(23):180-181.(In Chinese) 